\title{
Oxidative stress in the hippocampus during experimental seizures can be ameliorated with the antioxidant ascorbic acid
}

Ítala Mônica Sales Santos, ${ }^{1}$ Adriana da Rocha Tomé, ${ }^{2}$ Gláucio Barros Saldanha, ${ }^{3}$ Paulo Michel Pinheiro Ferreira, ${ }^{4}$ Gardenia Carmem Gadelha Militão ${ }^{5}$ and Rivelilson Mendes de Freitas 6 ,*

\begin{abstract}
${ }^{1}$ Acadêmica do Curso de Enfermagem; ${ }^{4}$ Professor Assistente do Setor de Histologia; 5 Professora Adjunta do Setor de Fisiologia; and 6 Professor Adjunto do Setor de Farmacologia; Universidade Federal do Piauí; Piauí, Brazil; ${ }^{2}$ Professora Adjunta da Universidade Estadual do Ceará; Ceará, Brazil; ${ }^{3}$ Professor do Curso de Farmácia da
\end{abstract} Faculdade Católica Rainha do Serão; Ceará, Brazil

Abbreviations: AA, ascorbic acid; i.p., intraperitoneal; $\mathrm{CHD}$, coronary heart disease; SE, status epilepticus; ROS, reactive oxygen species; $\mathrm{O}_{2}$, oxygen; CNS, central nervous system; $\alpha$-tocopherol, vitamin E; GLUT, glutamate; AA group, ascorbic acid group; $\mathrm{O}_{2}^{-}$, superoxide; $\mathrm{OH}$, hydroxyl radical; $\mathrm{NO}$, nitric oxide; $\mathrm{H}_{2} \mathrm{O}_{2}$, hydrogen peroxide; $\mathrm{H}_{2} \mathrm{O}$, water; SOD, superoxide dismutase; TBARS, thiobarbituricacid-reacting substances; $\mathrm{MDA}$, malondialdehyde; $\mathrm{H}_{3} \mathrm{PO}_{4}$, phosphoric acid; $\mathrm{NaNO}_{2}$, sodium nitrate; EDTA, ethylenediamine tetraacetic acid; KCN, potassium cyanide; S.E.M, standard error of the mean.

Key words: ascorbic acid, hippocampus, oxidative stress, pilocarpine, seizures

Ascorbic acid has many nonenzymatic actions and is a powerful water-soluble antioxidant. It protects low density lipoproteins from oxidation and reduces harmful oxidants in the central nervous system. Pilocarpine-induced seizures have been suggested to be mediated by increases in oxidative stress. Current studies have suggested that antioxidant compounds may afford some level of neuroprotection against the neurotoxicity of seizures. The objective of the present study was to evaluate the neuroprotective effects of ascorbic acid (AA) in rats, against the observed oxidative stress during seizures induced by pilocarpine. Wistar rats were treated with $0.9 \%$ saline (i.p., control group), ascorbic acid (500 mg/kg, i.p., AA group), pilocarpine (400 mg/kg, i.p., pilocarpine group), and the association of ascorbic acid $(500 \mathrm{mg} / \mathrm{kg}$, i.p.) plus pilocarpine $(400 \mathrm{mg} / \mathrm{kg}$, i.p.), $30 \mathrm{~min}$ before of administration of ascorbic acid (AA plus pilocarpine group). After the treatments all groups were observed for $6 \mathrm{~h}$. The enzyme activities as well as the lipid peroxidation and nitrite concentrations were measured using spectrophotometric methods and the results compared to values obtained from saline and pilocarpine-treated animals. Protective effects of ascorbic acid were also evaluated on the same parameters. In pilocarpine group there was a significant increase in lipid peroxidation and nitrite level. However, no alteration was observed in superoxide dismutase and catalase activities.

* Correspondence to: Rivelilson Mendes de Freitas; Campus Senador Helvídio Nunes de Barros; Rua Cícero Eduardo, s/n; Junco; Picos, Piauí 64.600-000 Brazil; Tel./Fax: +55.89.3422.4389; Email: rivelilson@ufpi.r

Submitted: 04/07/09; Revised: 04/20/09; Accepted: 04/20/09

Previously published online as an Oxidative Medicine and Cellular Longevity E-publication:

http://www.landesbioscience.com/journals/oximed/article/8876
Antioxidant treatment significantly reduced the lipid peroxidation level and nitrite content as well as increased the superoxide dismutase and catalase activities in hippocampus of adult rats after seizures induced by pilocarpine. Our findings strongly support the hypothesis that oxidative stress in hippocampus occurs during seizures induced by pilocarpine, proving that brain damage induced by the oxidative process plays a crucial role in seizures pathogenic consequences, and also imply that a strong protective effect could be achieved using ascorbic acid.

\section{Introduction}

In recent years, a great deal of attention has been given to antioxidants consumption and their role in reducing rates of chronic diseases such as epilepsy, cancer, coronary heart disease (CHD), stroke, diabetes and arthritis. ${ }^{1-3}$ It is suggested that the protective effect of antioxidant compounds is partly due to antioxidant nutrients such as ascorbic acid and carotenoids which inhibit lipid per-oxidation and oxidative cell damage. ${ }^{4,5}$ Reactive oxygen species have been implicated in the development of seizures and status epilepticus (SE) induced by pilocarpine. ${ }^{6}$ The mechanism behind seizures-induced oxidative stress is not well understood, but several explanations have been proposed. These include excitotoxicity associated with excessive neurotransmitter release, oxidative stress leading to free radical damage. ${ }^{6,7}$ Recently, several studies have examined the role of oxidative stress on pilocarpine-induced seizures, possibly via the formation of free radicals. ${ }^{8}$

Reactive oxygen species (ROS) are generated during oxidative metabolism and can inflict damage on all classes of cellular macromolecules (e.g., mitochondria, endoplasmic reticulum, etc.,), eventually leading to cell death. ${ }^{9}, 10$ Oxidative stress is attractive as a possible mechanism for the pilocarpine-induced seizures for many reasons. The brain processes large amounts of $\mathrm{O}_{2}$ in 
relatively small mass, and has a high content of substrates available for oxidation in conjunction with low antioxidant activities, making it extremely susceptible to oxidative damage. ${ }^{7111}$ In addition, certain regions of central nervous system (CNS), such as the hippocampus, may be particularly sensitive to oxidative stress because of their low endogenous levels of vitamin $\mathrm{E}$, an important biochemical antioxidant, relatively to other brain regions. ${ }^{12,13}$ Such a depressed defense system may be adequate under normal circumstances. However, under pro-oxidative conditions, such as during seizures, these low antioxidant defenses can predispose the brain to oxidative stress.

Seizures have been shown to cause an increase in the production of nitrite, ${ }^{14}$ a potent free radical known to be cytotoxic to neurons and glial cells. ${ }^{15}$ The role of oxidative stress in seizures induced by pilocarpine is also supported by studies showing beneficial effects of antioxidant compounds during seizures exposure. ${ }^{16,17}$ It has been reported the protective capacity of ascorbic acid against seizures-induced cerebral damage in adult rats. Its pretreatment strongly prevented the damage caused by aggressive radical species induced by seizures. ${ }^{4}$ Ascorbic acid can enters mitochondria by means of facilitative glucose transporter and confers mitochondrial protection against oxidative injury. Ascorbate has been implicated in many biological processes. It is a cofactor for several enzymatic steps in the synthesis of collagen, monoamines, amino acids, peptide hormones, and carnitine ${ }^{18,19}$ and plays an important role in antioxidant defense at a number of levels. It can directly metabolize reactive oxygen species, acts to maintain $\alpha$-tocopherol (vitamin E) in its reduced form, and mediates electron transfer to ascorbate-dependent peroxidases. ${ }^{19,20}$ Pathogenic dysfunction of tissues due to cell death via apoptosis is one of the important consequences of oxidative stress that could be diminished using antioxidant such as ascorbic acid. The objective of this study was to evaluate the potential effect of ascorbic acid on the attenuation of oxidative stress in the hippocampus of adult rat during acute phase of pilocarpine-induced seizures.

\section{Results}

Anticonvulsant effects of ascorbic acid in pilocarpine model. Pilocarpine induced the first seizure at $35.00 \pm 0.70 \mathrm{~min}$. All of the animals studied showed generalized tonic-clonic convulsions with status epilepticus (SE), and 30\% survived the seizures. All animals pretreated with the ascorbic acid selected for this study were observed for $6 \mathrm{~h}$ before pilocarpine injection and its manifested alterations in behavior, such as peripheral cholinergic signs (100\%), tremors (50\%), staring spells, facial automatisms, wet dog shakes, rearing and motor seizures (60\%), which develop progressively within $1-2 \mathrm{~h}$ into a long-lasting SE (60\%). Table 1 shows that when administered at the dose $(10 \mathrm{mg} / \mathrm{kg})$ before pilocarpine, ascorbic acid reduced by $50 \%$ the percentage of animals that seized $(\mathrm{p}<0.0001)$, increased $(154 \%)$ latency to the first seizure $(189.19 \pm 1.15 \mathrm{~min})[\mathrm{T}(46)=114.453 ; \mathrm{p}<0.0001]$ and increased $(60 \%)$ the survival percentage $(p<0.0001)$ as compared with the pilocarpine-treated group (Table 1). No animal that received injections of isotonic saline (control) or ascorbic acid alone showed seizure activity (Table 1).

\section{Table 1 Effect of pretreatment with ascorbic acid on pilocarpine-induced seizures and lethality in adult rats}

$\begin{array}{lcccc}\text { Groups } & \begin{array}{c}\text { Latency to } \\ \text { first seizures } \\ \text { (min) }\end{array} & \begin{array}{c}\text { Percentage } \\ \text { seizures }\end{array} & \begin{array}{c}\text { Percentage } \\ \text { survival }\end{array} & \begin{array}{c}\text { Number of } \\ \text { animals/ } \\ \text { group }\end{array} \\ \text { Pilocarpine } & 35.00 \pm 0.70 & 75 & 40 & 24 \\ \text { AA plus pilocarpine } & 189.19 \pm 1.15^{c} & 25^{a} & 100^{a} & 24 \\ \text { AA } & 00 & 00^{a, b} & 100^{a} & 24\end{array}$

Animals were divided in four groups and treated with ascorbic acid ( $500 \mathrm{mg} / \mathrm{kg}$, i.p., $\mathrm{n}=24)$ or $0.9 \%$ saline (i.p., $\mathrm{n}=24)$ and $30 \mathrm{~min}$ later, they received pilocarpine hydrochloride $(400 \mathrm{mg} / \mathrm{kg}$, i.p.), and in this 30-min interval rats were observed for the occurrence of any change in behavior. The treatments previously described represent the AA plus pilocarpine and pilocarpine groups, respectively. Other two groups received $0.9 \%$ saline (i.p., $n=36$, control group) or ascorbic acid alone $(500 \mathrm{mg} / \mathrm{kg}$, i.p., $\mathrm{n}$ $=24$, AA group). After the treatments, the animals were placed in $30 \mathrm{~cm} \times 30 \mathrm{~cm}$ chambers to record: latency to first seizure (any one of the behavioral indices typically observed after pilocarpine administration: wild running, clonus, tonus, clonic-tonic seizures), number of animals that died after pilocarpine administration. Previous work have shown that the numbers of convulsions and deaths occurring within 1 and $24 \mathrm{~h}$ postinjection always follow the same pattern, so we decided to observe the animals for $6 \mathrm{~h}$ as pilocarpine-induced convulsions occur in 30-60 min and deaths within $1-24 \mathrm{~h}$ after pilocarpine injection. Results for latency to first seizure are expressed as mean \pm S.E.M of the number of experiments shown in the table. Result for percentage seizures and percentage survival are expressed as percentages of the number of animals from each experimental group. ${ }^{a} p<0.0001$ as compared with pilocarpine group ( $\chi^{2}$-test). ${ }^{b} p<0.0001$ as compared with AA plus pilocarpine group $\left(\chi^{2}\right.$-test). ${ }^{c_{p}}<0.0001$ as compared with pilocarpine group (ANOVA and Student-Newman-Keuls test).

Lipid peroxidation level and nitrite content in the hippocampus of adult rats pretreated with ascorbic acid after pilocarpine-induced seizures. Effects of ascorbic acid in lipid peroxidation and nitrite concentrations during seizures induced by pilocarpine are presented in Figures 1 and 2. Lipid peroxidation was markedly increased in pilocarpine group as compared to corresponding values for the control group. During acute phase of seizures induced by pilocarpine it was observed a significant (89\%) increase in thiobarbituric-acidreacting substances $[\mathrm{T}(13)=11.678 ; \mathrm{p}<0.0001]$, when compared to the control group. Seizures induced by pilocarpine produced a significant increase in hippocampal nitrite content of 94\% [T(13) $=50.592 ; \mathrm{p}<0.0001]$, when compared to the control group (Fig. 2). Post hoc comparison of means indicated a significant decreases of 70 and $50 \%$ in hippocampus of rats pretreated with ascorbic acid in lipid peroxidation level $[\mathrm{T}(10)=11.385$; $\mathrm{p}<0.0001]$ and nitrite content $[\mathrm{T}(10)=51.471 ; \mathrm{p}<0.0001]$, when to compared with the pilocarpine group, respectively (Fig. 1). In addition, the pretreatment with ascorbic acid, $30 \mathrm{~min}$ before administration of pilocarpine also produced significant increases $43 \%$ in lipid peroxidation level $[\mathrm{T}(13)=2.709 ; \mathrm{p}<0.0179]$, when compared to corresponding values for the control group (Fig. 1). However, in nitrite content $[\mathrm{T}(13)=1.235 ; \mathrm{p}=\mathrm{N} . \mathrm{S}$. $]$ it produced no alteration, as compared to corresponding values for the control group (Fig. 2). Moreover, no animal that received injections of ascorbic acid alone showed alterations in lipid peroxidation level $[\mathrm{T}(13)=0.2037 ; \mathrm{p}=\mathrm{N} . \mathrm{S}$.$] and nitrite content [\mathrm{T}(13)=0.2166$; $\mathrm{p}=$ N.S.], when compared to the control group (Figs. 1 and 2).

Superoxide dismutase and catalase activities in the hippocampus of adult rats pretreated with ascorbic acid after pilocarpine-induced seizures. Figures 3 and 4 showed the ascorbic 


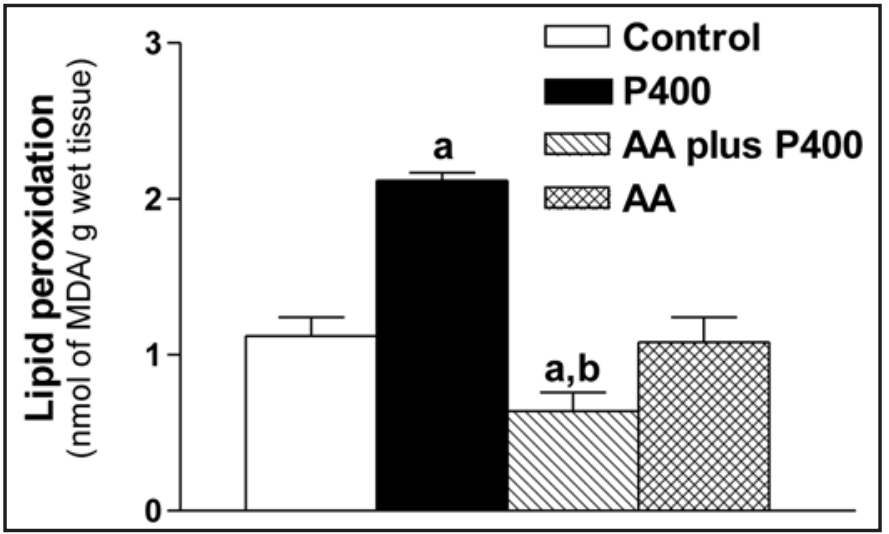

Figure 1. Effects of ascorbic acid (AA) in status of lipid peroxidation level in hippocampus of adult rats after seizures induced by pilocarpine. Male rats (250-280 g, 2 months old) were treated with a single dose of pilocarpine $(400 \mathrm{mg} / \mathrm{kg}$, intraperitoneal, i.p., $\mathrm{n}=6, \mathrm{P} 400)$, AA group with ascorbic acid $(500 \mathrm{mg} / \mathrm{kg}$, i.p., $\mathrm{n}=6$, VIT C) and the control animals with $0.9 \%$ saline (i.p., $\mathrm{n}=9$, Control). The AA plus pilocarpine group was treated with ascorbic acid $(500 \mathrm{mg} / \mathrm{kg}$, i.p.) $30 \mathrm{~min}$ after pilocarpine injection ( $400 \mathrm{mg} / \mathrm{kg}$, i.p., $\mathrm{n}=6$, AA plus $\mathrm{P} 400)$. The pilocarpine group was constituted by those rats that presented seizures, SE for over 30 min and that did not died within $6 \mathrm{~h}$. For neurochemical determinations of lipid peroxidation level, all groups were killed by decapitation $6 \mathrm{~h}$ after the treatment and their brains were dissected on ice to remove the hippocampus. The cerebral area studied was ultrasonically homogenized in $1 \mathrm{ml}$ of $0.05 \mathrm{M}$ phosphate buffer, $\mathrm{pH} 7.0$, and the homogenates $10 \%$ were centrifuged $(800 \mathrm{xg} / 20 \mathrm{~min})$ and the supernatant of the homogenates was used for lipid peroxidation level investigation. The lipid peroxidation level in the hippocampus during seizure activity was analyzed by measuring the thiobarbituric-acid-reacting substances (TBARS) in homogenates, as previously described by Draper and Hadley. ${ }^{47}$ Results are expressed as means + S.E.M. for the number of animals shown inside in parenthesis. Results were expressed as nmol of malondialdehyde (MDA)/g wet tissue. The Student-Newman-Keuls test was used for multiple comparisons of means of two groups of data. Differences in experimental groups were determined by two-tailed analysis of variance. Differences were considered significant at $p<0.05$. ${ }^{a} p<0.05$ as compared to control animals (t-Student-Neuman-Keuls test); ${ }^{b} p<0.05$ as compared to pilocarpine group (t-Student-Neuman-Keuls test).

acid effects in superoxide dismutase and catalase activities in the hippocampus of adult rats pretreated with ascorbic acid after acute phase of seizures induced by pilocarpine. Superoxide dismutase $[\mathrm{T}(13)=0.0393 ; \mathrm{p}=\mathrm{N} . \mathrm{S}$.$] and catalase [\mathrm{T}(13)=0.1737 ; \mathrm{p}=\mathrm{N} . \mathrm{S}$. $]$ activities in the hippocampus during acute phase of seizures was not markedly altered in pilocarpine group, when compared to corresponding values for the control group. However, post hoc comparison of means indicated a significant (25\%) increase in hippocampal superoxide dismutase activity of rats pretreated with ascorbic acid $[\mathrm{T}(10)=2.303 ; \mathrm{p}<0.0440]$ in comparison to the pilocarpine group. The pretreatment with ascorbic acid also produced a significant increase in hippocampal catalase activity of $31 \%$ [T $(10)=3.698 ; \mathrm{p}<0.0041]$ when compared to the pilocarpine group. In addition, the pretreatment with ascorbic acid, 30 min before administration of pilocarpine also produced significant increases 27 and 35\% in superoxide dismutase [T(13) $=2.203 ; \mathrm{p}<0.0462]$ and catalase activities $[\mathrm{T}(13)=5.108$; $\mathrm{p}<0.0002]$, when compared with corresponding values for the

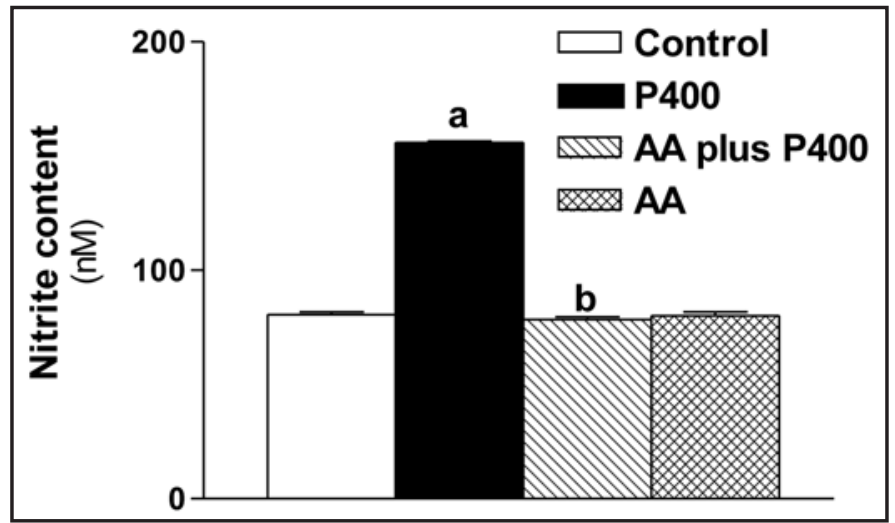

Figure 2. Effects of ascorbic acid (AA) in status of nitrite content in hippocampus of adult rats after seizures induced by pilocarpine. Male rats (250-280 g, 2-months-old) were treated with a single dose of pilocarpine ( $400 \mathrm{mg} / \mathrm{kg}$, intraperitoneal, i.p., $\mathrm{n}=6, \mathrm{P} 400$ ), AA group with ascorbic acid $(500 \mathrm{mg} / \mathrm{kg}$, i.p., $\mathrm{n}=6, \mathrm{AA})$ and the control animals with $0.9 \%$ saline (i.p., $n=9$, Control). The AA plus pilocarpine group was treated with ascorbic acid $(500 \mathrm{mg} / \mathrm{kg}$, i.p.) $30 \mathrm{~min}$ after pilocarpine injection (400 mg/kg, i.p., $\mathrm{n}=6$, AA plus P400). The cerebral area studied was ultrasonically homogenized in $1 \mathrm{ml}$ of $0.05 \mathrm{M}$ phosphate buffer, $\mathrm{pH} 7.0$, and the homogenates $10 \%$ were centrifuged $(800 \mathrm{~g} / 20 \mathrm{~min})$ and the supernatant of the homogenates was used for nitrite level investigation. The nitrite content in the hippocampus during seizure activity was analyzed by measuring the nitrite and nitrate in homogenates, as previously described by Green et al. ${ }^{51}$ Results are expressed as means + S.E.M. for the number of animals shown inside in parenthesis. Results were expressed as $\mathrm{nM}$. The Student-Newman-Keuls test was used for multiple comparisons of means of two groups of data. Differences in experimental groups were determined by two-tailed analysis of variance. Differences were considered significant at $p<0.05$. ${ }^{a} p<0.05$ as compared to control animals (t-Student-Neuman-Keuls test); ${ }^{b} p<0.05$ as compared to P400 group (t-Student-Neuman-Keuls test).

control group (Figs. 3 and 4). However, none of the adult rats that received ascorbic acid alone (AA group) showed alterations in superoxide dismutase $[\mathrm{T}(13)=0.1699 ; \mathrm{p}=$ N.S. $]$ and catalase $[\mathrm{T}(13)=0.5364 ; \mathrm{p}=\mathrm{N} . \mathrm{S}$.] activities, when compared to the control group (Figs. 3 and 4).

\section{Discussion}

It is well known that reactive oxygen species (ROS) formation increases during seizures, and the removal of these formed species depends on antioxidant systems. ${ }^{21,22}$ If the rise in the level of ROS exceeds the antioxidant capacity to neutralize them, then cell lipids, proteins, and even DNA material may suffer oxidative damage. ${ }^{10,23}$ Vitamins $C$ (ascorbic acid) and $E$ ( $\alpha$-tocopherol) are exogenous powerful antioxidant molecules that act together with other endogenous antioxidant systems within tissue cells in order to scavenge the formed ROS. ${ }^{24,25}$ Furthermore, several studies have shown that antioxidant vitamin supplementation decreases oxidative damage in human subjects. ${ }^{26,27}$

In the present study we have examined whether the treatment with ascorbic acid can alter in the lipid peroxidation level, nitrite content, superoxide dismutase and catalase activities in hippocampus observed during seizures induced by pilocarpine in adult rats. Generation of reactive oxygen species is currently viewed 


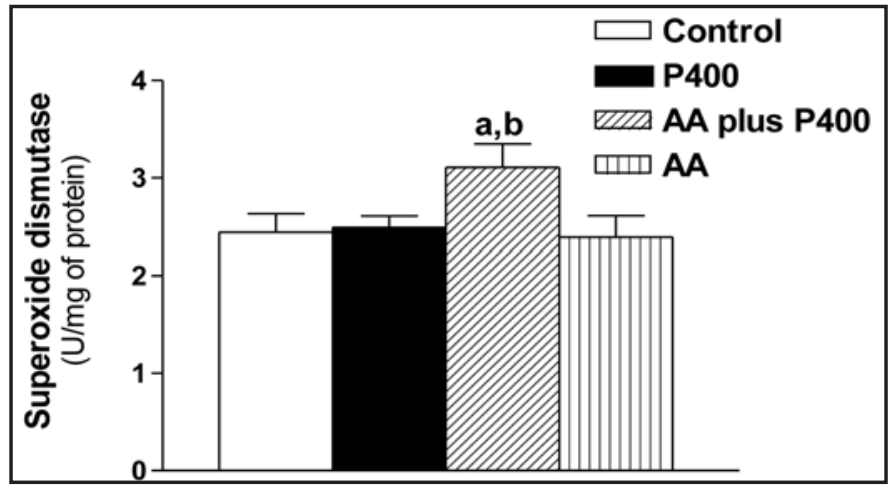

Figure 3. Effects ascorbic acid (AA) in superoxide dismutase activities in hippocampus of adult rats after seizures induced by pilocarpine. Male rats (250-280 g, 2 months old) were treated with a single dose of pilocarpine $(400 \mathrm{mg} / \mathrm{kg}$, intraperitoneal, i.p., $\mathrm{n}=6, \mathrm{P} 400), \mathrm{AA}$ group with ascorbic acid $(500 \mathrm{mg} / \mathrm{kg}$, i.p., $\mathrm{n}=6, \mathrm{AA})$ and the control animals with $0.9 \%$ saline (i.p., $n=9$, Control). The AA plus pilocarpine group was treated with ascorbic acid $(500 \mathrm{mg} / \mathrm{kg}$, i.p.) 30 min after pilocarpine injection ( $400 \mathrm{mg} / \mathrm{kg}$, i.p., $\mathrm{n}=6$, AA plus P400). The cerebral area studied was ultrasonically homogenized in $1 \mathrm{ml}$ of $0.05 \mathrm{M}$ phosphate buffer, $\mathrm{pH}$ 7.0 , and the homogenates $10 \%$ were centrifuged $(800 \mathrm{xg} / 20 \mathrm{~min})$ and the supernatant of the homogenates was used for superoxide dismutase activity investigation. The superoxide dismutase activity in the hippocampus during seizure activity was analyzed by measuring the superoxide dismutase activity in homogenates, as previously described by Flohe and Otting, 1989. Results are expressed as means + S.E.M. for the number of animals shown inside in parenthesis. Results were expressed as $\mathrm{U} / \mathrm{mg}$ of protein. The Student-Newman-Keuls test was used for multiple comparisons of means of two groups of data. Differences in experimental groups were determined by two-tailed analysis of variance. Differences were considered significant at $p<0.05$. a $p<0.05$ as compared to control animals (t-Student-Neuman-Keuls test); $b_{p}<0.05$ as compared to pilocarpine group (t-Student-Neuman-Keuls test).

as one of the process through which epileptic activity exert their deleterious effects on brain. ${ }^{28}$ These reactive oxygen species in the absence of an efficient defense mechanism cause peroxidation of membrane poly unsaturated fatty acids. ${ }^{29}$ Brain is particularly susceptible to peroxidation due to simultaneous presence of high levels of poly unsaturated fatty acids and iron, ${ }^{29,30}$ which is the target of free radical damage. We have recorded the rise in lipid peroxidation level in hippocampus homogenate of rats, after 6 $\mathrm{h}$ of acute phase of seizures. This is reflected by rise in TBARS level which may be related to its intermediate free radicals formed during seizures induced by pilocarpine.

Literature has shown that seizures induced by pilocarpine produces changes in nitric oxide metabolism increased the production of their metabolites (nitrite and nitrate). Its metabolites can interacts with glutamatergic receptors to produced part of its stimulatory action on the CNS. ${ }^{31,32}$ The fall in nitrite content, after pretreatment with ascorbic acid, is most readily explained as a consequence of inhibiting formation of radicals, scavenges reactive oxygen species and lipid peroxidation products. ${ }^{32}$ Increased free radicals and elevated nitrite levels may cause lipid peroxidation on hippocampus of rats during seizures. ${ }^{14,33}$

Histopathological studies using ascorbic acid pretreated animals 30 min before pilocarpine injection have shown a $60 \%$ decrease in

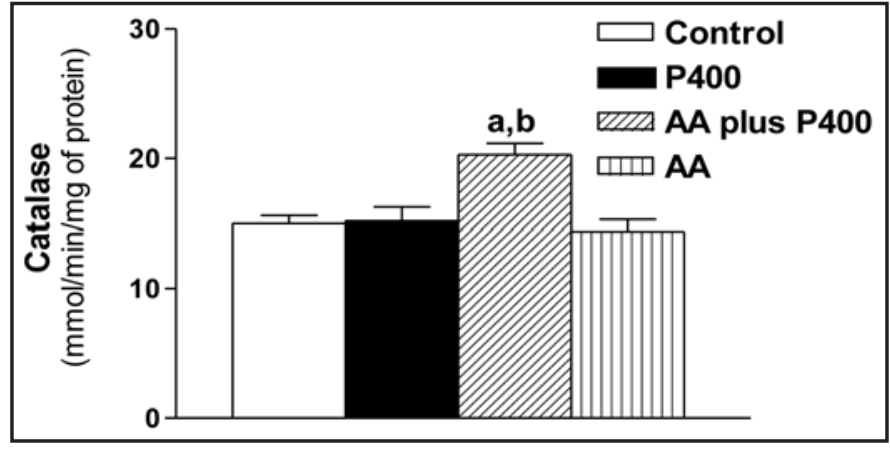

Figure 4. Effects of ascorbic acid (AA) in catalase activities in hippocampus of adult rats after seizures induced by pilocarpine. Male rats $(250-280 \mathrm{~g}$, 2 months old) were treated with a single dose of pilocarpine $(400 \mathrm{mg} / \mathrm{kg}$, intraperitoneal, i.p., $\mathrm{n}=6$, P400), AA group with ascorbic acid $(500 \mathrm{mg} /$ $\mathrm{kg}$, i.p., $\mathrm{n}=6$, VIT C) and the control animals with $0.9 \%$ saline (i.p., $\mathrm{n}=$ 9, Control). The AA plus pilocarpine group was treated with ascorbic acid $(500 \mathrm{mg} / \mathrm{kg}$, i.p.) $30 \mathrm{~min}$ after pilocarpine injection $(400 \mathrm{mg} / \mathrm{kg}$, i.p., $\mathrm{n}$ $=6, \mathrm{AA}$ plus $\mathrm{P} 400$ ). The cerebral area studied was ultrasonically homog-

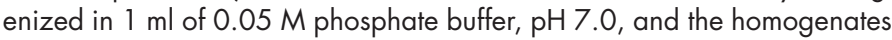
$10 \%$ were centrifuged $(800 \mathrm{xg} / 20 \mathrm{~min})$ and the supernatant of the homogenates was used for catalase activity investigation. The catalase activity in the hippocampus during seizure activity was analyzed by measuring the catalase activity in homogenates, as previously described by Chance and Maehly, 1955. Results are expressed as means \pm S.E.M. for the number of animals shown inside in parenthesis. Results were expressed as mmol/ $\mathrm{min} / \mathrm{mg}$ of protein. The Student-Newman-Keuls test was used for multiple comparisons of means of two groups of data. Differences in experimental groups were determined by two-tailed analysis of variance. Differences were considered significant at $p<0.05$. ${ }^{a} p<0.05$ as compared to control animals (t-Student-Neuman-Keuls test); ${ }^{b} p<0.05$ as compared to pilocarpine group (t-Student-Neuman-Keuls test).

the number of animals that presented hippocampal brain damaged after seizures (data not shown). Following the experimental protocol, we observed that none of the animals which received ascorbic acid alone presented brain damage. However, $80 \%$ of the animals which had seizures, developed to SE and did not died within $24 \mathrm{~h}$ presented brain damage. In addition, the pilocarpine group presented hippocampal area at a $60 \%$ damage. On the other hand, in the hippocampus of ascorbic acid pretreated animals, the damage was only $12 \%$ (data not shown). These findings support the theory of the oxidative stress involvement in the start of seizures by the increase of free radical production. Moreover, they suggest a neuroprotective activity of ascorbic acid by the removal of free radicals produced during pilocarpine-induced seizures. Thus, the results suggest that oxidative stress mediated by pilocarpine exerts its pathologic effects during seizures and also that the neuroprotective and anticonvulsive role of ascorbic acid can be mediated by a reduction in lipid peroxidation levels and nitrite content. Possibly, this reduction is due to the modulatory activity of ascorbic acid in the antioxidant enzymes (superoxide dismutase and catalase) in the hippocampus of adult rats. Further studies using more specific immunohistochemistry and neurocheminal techniques can demonstrate the ascorbic acid effects during seizures.

Superoxide dismutase and catalase activities can protect against seizures induced by pilocarpine. However, there were no chenges in hippocampal superoxide dismutase and catalase activities during 
acute phase of seizures, suggesting that these enzymes cannot be activated during their phase of seizures induced by pilocarpine, and other antioxidant systems can be responsible for inhibition of acute epileptic activity. It has been demonstrated that pretreatment with ascorbic acid during acute phase of seizures induced by pilocarpine produces increase in superoxide dismutase and catalase activities in hippocampus of rats. The increase in antioxidant enzymes activities, after pretreatment with ascorbic acid, is most readily explained as a necessary consequence of inhibiting formation of radicals during convulsive process, and induces the glutathione reduced synthesis and other antioxidant enzymes (e.g., glutathione peroxidase and glutathione reductase) that exert neuroprotective effects during limbic seizures. $32,34,35$

An elevation in free radical formation can be accompanied by an immediate compensatory increase in the activities of the free radical scavenging enzymes. ${ }^{36}$ Previous studies showed an increased in catalase activity in the hippocampus during a 24 $\mathrm{h}$ period of acute phase of seizures. ${ }^{14,36}$ Other study showed an increase in catalase activity after $1 \mathrm{~h}$ of seizures. In addition, during the convulsive process, neuronal activities changes are accompanied by alterations in the cerebral metabolic rate that induced modification in the regional cerebral blood flow. ${ }^{37}$ Our results have not shown any alterations in superoxide dismutase and catalase activities within $6 \mathrm{~h}$ of acute phases of seizures. Considering that an increased metabolic demand can be observed during the epileptic activity we can suggest that activity of these enzymes are not modified during this period of acute phase of seizures. This finding might indicate that the antioxidant metabolism in this structure remains unaltered for $6 \mathrm{~h}$ of seizures induced by pilocarpine and that the pretreatment with ascorbic acid can produce an increase in the antioxidant enzymes activity. Its compensatory mechanisms against oxidative stress observed during seizures can explain the anticonvulsant actions of ascorbic acid during behavioral studies. The seizures induced by pilocarpine are prevented by ascorbic acid, suggesting a role of free radical in controlling seizures installation and propagation. In fact, we found that pretreatment with ascorbic acid is able to inhibit pilocarpine-induced seizures, SE and mortality of adult rats. In addition, the present data suggest evidence that free radical formation have a relevant role in the propagation and/or maintenance of convulsive activity. An increase in antioxidant enzymes activities, while free radical formation reduces, produces a significant decrease in the susceptibility to seizures induced by pilocarpine, the results suggest that ascorbic acid can present an anticonvulsant effect against pilocarpine-induced seizures.

Ascorbic acid administration to convulsive animals has been shown to protect hippocampus against oxidative stress. As an electron donor, ascorbic acid acts as a cofactor for eight enzymes involved in collagen hydroxylation, biosynthesis of carnitine and norepinephrine, tyrosine metabolism and amidation of peptide hormones (reviewed in ref. 38). Ascorbic acid has many nonenzymatic actions as well. It is a powerful water-soluble antioxidant, it protects low density lipoproteins from oxidation, reduces harmful oxidants in the stomach and promotes iron absorption (reviewed in refs. 39 and 40). Results of animal studies demonstrate that ascorbic acid can reduce damage to neurons caused by free radicals that are produced by inflammatory process and in neurodegenerative diseases.

Ascorbic acid can be easily oxidized to the unstable dehydroascorbic acid, which is transported into the cells by glucose transporters GLUT $_{1}$ and GLUT $_{3}$, and in insulin-sensitive tissues, also by $\mathrm{GLUT}_{4}$, where it is rapidly reduced to ascorbic acid by glutaredoxin and thioredoxin reductase. ${ }^{41}$ Brain, adrenal cortex, liver, spleen, pancreas and kidney tissues concentrate ascorbic acid for yet unknown reasons. Recent results have shown that endothelial cells also recycle and accumulate ascorbate by glutathion-dependent mechanisms. ${ }^{42}$ These data suggest that this mechanism may be similar in neuronal cells and may be modified in the hippocampus during seizures.

Ascorbic acid is a powerful water-soluble antioxidant. Therefore its biological functions are not limited solely to one environment. In addition to reduction of lipid peroxidantion and nitrite contents, it has been shown to be involved in the recycling of other antioxidants in the body including vitamin $\mathrm{E}$ and lipoic acid and in modulation of enzymes activities superoxide dismutase and catalase. Thus, ascorbic acid represents a possible neuroprotective agent against risk factors of acute phase of seizures induced by pilocarpine. The results suggest the involvement of lipid peroxidation, nitrite and changes in antioxidant enzymatic systems in the mechanism of seizures induced by pilocarpine in rats. Ascorbic acid will provide further insights for neuroprotection and may lead to the development of effective therapeutic strategies against it, through modulation of brain antioxidant enzyme activities.

Recent studies have demonstrated that ascorbate, catalase and SOD attenuated seizures-induced neurotoxicity, as assessed by DA and GABA uptake. Ascorbate, an antioxidant watersoluble vitamin, directly scavenges superoxide anion and hydroxyl radical while SOD, an antioxidant mitochondrial and/or cytosolic enzyme, catalyses the conversion of superoxide anion to hydrogen peroxide and water. ${ }^{43}$ These data are consistent with findings from previous studies that evaluated other antioxidants and their role in oxidative stress and neuronal toxicity. Thus, these data support previous findings from neuron-glia co-cultures that glia protect neurons from $\mathrm{H}_{2} \mathrm{O}_{2}$ toxicity. ${ }^{44}$ Previous studies have shown that ascorbic acid, a predominantly neuronal antioxidant, ${ }^{45}$ compensates for loss of GSH after synthesis inhibition by nitrite and nitrate. Here, we show that ascorbic acid also compensates for loss of other components of the antioxidant network, including superoxide dismutase and catalase. These findings indicate the importance of neuronal antioxidants in providing a permissive, yet protective environment for signaling by $\mathrm{H}_{2} \mathrm{O}_{2}$ and other ROS such as nitrite and nitrate. Elucidation of ascorbic acid transport and function in neurodegenerative diseases may lead to development of new drugs acting on ascorbic acid transporters to increase the antioxidant capacity during seizure activity.

\section{Materials and Methods}

Animals and experimental procedures. Adult male Wistar rats $(250-280 \mathrm{~g})$ maintained in a temperature controlled room $\left(26^{\circ} \mathrm{C}\right)$ with a 12 -h light/dark cycle with food and water ad libitum 
were used. All experiments were performed according to the Guide for the care and use of laboratory the US Department of Health and Human Services, Washington, DC (1985). The following substances were used: pilocarpine hydrochloride and ascorbic acid (Sigma, Chemical USA). All doses are expressed in milligrams per kilogram and were administered in a volume of $10 \mathrm{ml} / \mathrm{kg}$ injected intraperitoneally (i.p.). In a set of experiments, the animals were divided in four groups and treated with ascorbic acid $(500 \mathrm{mg} / \mathrm{kg}$, i.p., $\mathrm{n}=24)$ or $0.9 \%$ saline (i.p., $\mathrm{n}=24)$ and $30 \mathrm{~min}$ later, they received pilocarpine hydrochloride $(400 \mathrm{mg} / \mathrm{kg}$, i.p.), and in this 30-min interval rats were observed for the occurrence of any change in behavior. The treatments previously described represent the ascorbic acid plus pilocarpine and pilocarpine groups, respectively. Other two groups received $0.9 \%$ saline (i.p., $\mathrm{n}=36$, control group) or ascorbic acid alone $(500 \mathrm{mg} / \mathrm{kg}$, i.p., $\mathrm{n}=24$, AA group). After the treatments, the animals were placed in $30 \mathrm{~cm}$ x $30 \mathrm{~cm}$ chambers to record: latency to first seizure (any one of the behavioral indices typically observed after pilocarpine administration: wild running, clonus, tonus, clonic-tonic seizures), ${ }^{46}$ number of animals that died after pilocarpine administration. Previous work have shown that the numbers of convulsions and deaths occurring within 1 and $24 \mathrm{~h}$ postinjection always follow the same pattern, so we decided to observe the animals for $6 \mathrm{~h}$ as pilocarpine-induced convulsions occur in 30-60 min and deaths within 1-24 h after pilocarpine injection. The survivors were killed by decapitation and their brains dissected on ice to remove hippocampus for neurochemical determinations. The pilocarpine group was constituted by those rats that presented seizures; SE for over $30 \mathrm{~min}$ and that did not died within $6 \mathrm{~h}$.

The drug dosages were determined from both dose-response studies, including pilocarpine (data not shown), and observations of the doses currently used in animals studies in the literature. The doses used are not equivalent to those used by humans because rats have different metabolic rates.

Lipid peroxidation levels determinations in the hippocampus of adult rats pretreated with ascorbic acid after pilocarpineinduced seizures. A literature review revealed that there are articles that address the role of oxidative stress in neurological disorders, including seizure models induced by pilocarpine in which the modulation of the pro-oxidant/antioxidant balance by seizures per se and by antioxidant agents is discussed. ${ }^{4,16,27}$ However, the critical role of oxidative stress in this seizure models is not uniform. A study carried out by Walz et al. ${ }^{10}$ showed that after status epilepticus induced by pilocarpine can be observed an increase in lipid peroxidation level in hippocampus of Wistar rats. Based in this fact, we decided to investigate the lipid peroxidation level in the hippocampus of adult rats pretreated with ascorbic acid after pilocarpine-induced seizures. Therefore, there is a need for a study that will address these issues. For all of the experimental procedures, $10 \%(\mathrm{w} / \mathrm{v})$ homogenates of the area of the brain investigated were prepared for all groups. Lipid peroxidation levels in the AA plus pilocarpine group $(n=6)$, pilocarpine group $(n=6)$, AA group $(\mathrm{n}=6)$ and control animal $(\mathrm{n}=9)$ were analyzed by measuring the thiobarbituric-acid-reacting substances (TBARS) in homogenates, as previously described by Draper and Hadley. ${ }^{47}$ Briefly, the samples were mixed with $1 \mathrm{~mL} 10 \%$ trichloroacetic acid and 1 $\mathrm{mL} 0.67 \%$ thiobarbituric acid. They were then heated in a boiling water bath for $15 \mathrm{~min}$ and butanol $(2: 1, \mathrm{v} / \mathrm{v})$ was added to the solution. After centrifugation ( $800 \mathrm{xg}, 5 \mathrm{~min})$, thiobarbituric-acidreacting substances were determined from the absorbance at 535 $\mathrm{nm}$. The results above were expressed as nmol of malondialdehyde (MDA)/g wet tissue.

Nitrite content determinations in the hippocampus of adult rats pretreated with ascorbic acid after pilocarpine-induced seizures. Researches verified an increase in nitrite/nitrate content in mice brain after pilocarpine-induced seizures, ${ }^{48}$ in hippocampus of adult rats after seizures, ${ }^{49}$ and in cerebrospinal fluid of patients with rotavirus gastroenteritis induced convulsion. ${ }^{50}$ According to this data, we decided to measure the nitrite content in rats brain pretreated with ascorbic acid during seizure activity. To determine nitrite contents of control rats $(n=9)$, AA plus pilocarpine group $(n=6)$, pilocarpine group $(n=6)$ and AA group $(n=6)$, the $10 \%$ $(\mathrm{w} / \mathrm{v})$ homogenates were centrifuged $(800 \mathrm{xg}, 10 \mathrm{~min})$. The supernants were collected, and nitric oxide production was determined based on the Griess reaction. ${ }^{51}$ Briefly, $100 \mu \mathrm{L}$ supernatant was incubated with $100 \mu \mathrm{L}$ of the Griess reagent at room temperature for $10 \mathrm{~min} . \mathrm{A}_{550}$ was measured using a microplate reader. Nitrite concentration was determined from a standard nitrite curve generated using $\mathrm{NaNO}_{2}$. The results above were expressed as $\mathrm{nM}$.

Superoxide dismutase and catalase activity determinations in the hippocampus of adult rats pretreated with ascorbic acid after pilocarpine-induced seizures. A literature review revealed articles that address the role of antioxidant enzymes and oxidative stress in neurological disorders, including those involving different seizure models where the modulation of the pro-oxidant/antioxidant balance by seizures per se and by antioxidant agents is discussed. However, the critical role of antioxidant enzymes in all seizure models is not uniform. Therefore, there is a need for a study about the superoxide and catalase activity during seizures induced by pilocarpine that will address this issue. ${ }^{52-54}$

The hippocampus was ultrasonically homogenized in $1 \mathrm{~mL}$ $0.05 \mathrm{M}$ sodium phosphate buffer, $\mathrm{pH}$ 7.0. Protein concentration was measured by the method of Lowry et al..$^{55}$ The $10 \%$ homogenates were centrifuged $(800 \mathrm{xg}, 20 \mathrm{~min})$, and the supernants used to assay superoxide dismutase (SOD) and catalase. SOD activity in the AA plus pilocarpine group $(n=6)$, pilocarpine group $(\mathrm{n}=6)$ and AA group $(\mathrm{n}=6)$ and control animals $(\mathrm{n}=9)$ was assayed by using xanthine and xanthine oxidase to generate superoxide radicals. ${ }^{56}$ They react with 2,4-iodophenyl-3,4-nitophenol-5-phenyltetrazolium chloride to form a red formazan dye. The degree of inhibition of this reaction was measured to assess SOD activity. The standard assay substrate mixture contained $3.0 \mathrm{~mL}$ xanthine $(500 \mu \mathrm{M}), 7.44 \mathrm{mg}$ cytochrome $c, 3.0 \mathrm{~mL}$ $\mathrm{KCN}(200 \mu \mathrm{M})$, and $3.0 \mathrm{~mL}$ EDTA $(1 \mathrm{mM})$ in $18.0 \mathrm{~mL} 0.05$ $\mathrm{m}$ sodium phosphate buffer, $\mathrm{pH}$ 7.0. The sample aliquot $(20 \mu \mathrm{L})$ was added to $975 \mu \mathrm{L}$ of the substrate mixture plus $5 \mu \mathrm{L}$ xanthine oxidase. After $1 \mathrm{~min}$, the initial absorbance was recorded and the timer was started. The final absorbance after 6 min was recorded. The reaction was followed at $550 \mathrm{~nm}$. Purified bovine erythrocyte SOD (Randox Laboratories, Belfast, Northern Ireland, UK) 
was used under identical conditions to obtain a calibration curve showing the correlation of the inhibition percentage of formazan dye formation and SOD activity. SOD activity in the samples was determined from this curve, and the results expressed as $\mathrm{U} / \mathrm{mg}$ of protein.

Catalase activity was measured in the AA plus pilocarpine group $(n=6)$, pilocarpine group $(n=6)$ and AA group $(n=6)$ and control $(n=9)$ groups by the method that uses $\mathrm{H}_{2} \mathrm{O}_{2}$ to generate $\mathrm{H}_{2} \mathrm{O}$ and $\mathrm{O}_{2}{ }^{57}$ Protein concentration was measured by the method of Lowry et al. ${ }^{55}$ The activity was measured by the degree of this reaction. The standard assay substrate mixture contained $0.30 \mathrm{~mL} \mathrm{H}_{2} \mathrm{O}_{2}$ in $50 \mathrm{~mL} 0.05 \mathrm{M}$ sodium phosphate buffer, $\mathrm{pH}$ 7.0. The sample aliquot $(20 \mu \mathrm{L})$ was added to $980 \mu \mathrm{L}$ of the substrate mixture. The initial absorbance was recorded after $1 \mathrm{~min}$, and the final absorbance after $6 \mathrm{~min}$. The reaction was followed at $230 \mathrm{~nm}$. A standard curve was established using purified catalase (Sigma, St Louis, MO, USA) under identical conditions. All samples were diluted with $0.1 \mathrm{mmol} / \mathrm{L}$ sodium phosphate buffer $(\mathrm{pH} 7.0)$, to provoke a $50 \%$ inhibition of the diluent rate (i.e., the uninhibited reaction). Results are expressed as $\mathrm{mmol} / \mathrm{min} / \mathrm{mg}$ of protein. ${ }^{58}$

Statistical analysis. Results of latency to first seizure and neurochemical alterations were compared using ANOVA and the Student-Newman-Keuls test as post hoc test, because these results show a parametric distribution. The number of animals that seized and the number that survived were calculated as percentages (percentage seizures and percentage survival, respectively), and compared with a nonparametric test $\left(\chi^{2}\right)$. In all situations statistical significance was reached at $\mathrm{p}$ less-than-or-equals, slant 0.05 . The statistical analyses were performed with the software GraphPad Prism, Version 3.0 for Windows, GraphPad Software (San Diego, CA, USA).

\section{References}

1. Carr AC, Frei B. Toward a new recommended dietary allowance for vitamin C based on antioxidant and health effects in humans. Am J Clin Nutr 1999; 69:1086-107.

2. Simon JA, Hudes ES, Tice JA. Relation of serum ascorbic acid to mortality among US adults. J Am Coll Nutr 2001; 20:255-63.

3. Ziegler RG. Vegetables, fruits and carotenoids and the risk of cancer. Am J Clin Nutr 1991; 53:251-9.

4. Xavier SML, Barbosa CO, Barros DO, et al. Vitamin C antioxidant in hippocampus of adult Wistar rats after seizures and status epilepticus induced by pilocarpine. Neurosci Lett 2007; 420:76-9.

5. Steinmetz KA, Potter JD. Vegetables, fruit and cancer II. Mechanisms. Cancer Causes Control 1991; 2:427-42.

6. Andreoli SP, Mallett CP. Disassociation of oxidant-induced ATP depletion and DNA damage from early cytotoxicity in LLC-PK1 cells. American Journal of Physiology 1997; 272:729-35.

7. Liang LP, Beaudoin ME, Fritz MJ, et al. Kainate-induced seizures, oxidative stress and neuronal loss in aging rats. Neuroscience 2007; 147:1114-8.

8. Heaton MB, Mitchell JJ, Paiva M. Amelioration of ethanol-induced neurotoxicity in the neonatal rat central nervous system by antioxidant therapy. Alcohol Clin Exp Res 2000; 24:512-8.

9. McCord JM. Superoxide radical: controversies, contradiction and paradoxes. Proc Soc Exp Biol Med 1989; 209:112-7.

10. Walz R, Moreira JCF, Benfato MS, Quevedo J, Schorer N, Vianna MMR, et al. Lipid peroxidation in hippocampus early and late after status epilepticus induced by pilocarpine of kainic acid in Wistar rats. Neuroscience Letters 2000; 291:179-82.

11. Bergamini CM, Gambetti S, Dondi A, et al. Oxygen, reactive oxygen species and tissue damage, Current Pharmaceutical Design 2004; 10:1611-26,

12. Gottlieb M, Leal-Campanario R, Campos-Esparza MR, et al. Neuroprotection by two polyphenols following excitotoxicity and experimental ischemia. Neurobiol Dis 2006; 23:374-86.
13. Henderson GI, Chen JJ, Schenker S. Ethanol, oxidative stress, reactive aldehydes, and the fetus. Frontiers in Bioscience: A Journal and Virtual Library 1999; 4:541-50.

14. Freitas RM, Souza FCF, Vasconcelos SMM, et al. Oxidative stress in the hippocampus after status epilepticus in rats. FEBS J 2005; 272:1307-12.

15. Baraona E, Zeballos GA, Shoichet L, et al. Ethanol consumption increases nitric oxide production in rats, and its peroxynitrite mediated toxicity is attenuated by polyenylphosphatidylcholine. Alcohol Clin Exp Res 2002; 26:883-9.

16. Barros DO, Xavier SM, Barbosa CO, et al. Effects of the vitamin E in catalase activities in hippocampus after status epilepticus induced by pilocarpine in Wistar rats. Neurosci Lett 2007; 416:227-30.

17. Zugno AI, Stefanello FM, Scherer EB, et al. Guanidinoacetate decreases antioxidant defenses and total protein sulfhydryl content in striatum of rats. Neurochem Res 2008; 33:1804-10.

18. Wilkinson SR, Prathalingam SR, Taylor MC, et al. Vitamin C biosynthesis in trypanosomes: A role for the glycosome. PNAS 2005; 102:11645-50.

19. Powers SK, Ji LL, Leeuwenburgh C. Exercise training-induced alterations in skeletal muscle antioxidant capacity: a brief review. Med Sci Sports Exerc 1999; 31:987-97.

20. Zoppi CC, Hohl R, Silva FC, et al. Vitamin C and E Supplementation Effects in Professional Soccer Players Under Regular Training. Med Sci Sports Exerc 2006; 3:37-44.

21. Packer L. Oxidants, antioxidants, nutrients and the athlete. J Sports Sci 1997; 15:353-63.

22. Evans WJ. Vitamin E, vitamin C and exercise. Am J Clin Nutr 2000; 72:521-647.

23. Freitas RM, Nascimento VS, Vasconcelos SMM, et al. Catalase activity in cerebellum, hippocampus, frontal cortex and striatum after status epilepticus induced by pilocarpine in Wistar rats. Neurosci Lett 2004; 365:102-5.

24. Colgan M. The effects of micronutrient supplementation on athletic performance. In: Katch FI, (Ed.,) Sport, Health and nutrition. Human Kinetics 1986; 21-50.

25. Jakeman P, Maxwell S. Effects of antioxidant vitamin supplementation on muscle function after eccentric exercise. Eur J Appl Physiol 1993; 67:426-30.

26. Kanter MM, Nolte LA, Holloszy JO. Effects of an antioxidant vitamin mixture on lipid peroxidation at rest and postexercise. J Appl Physiol 1993; 74:965-9.

27. Santos LF, Freitas RL, Xavier SM, et al. Neuroprotective actions of vitamin C related to decreased lipid peroxidation and increased catalase activity in adult rats after pilocarpineinduced seizures. Pharmacol Biochem Beh 2008; 89:1-5.

28. Castagne V, Gastschi M, Lefevre K, et al. Relationship between neuronal death and cellular redox status, focus on the developing nervous system. Prog Neurophysiol 1999; 59:397-423

29. Halliwell B, Gutteridge JMC. Free Radicals in Biology and Medicine, Oxford Science Publications, London 1999.

30. Halliwell B, Gutteridge JMC, Lipid peroxidation: a radical chain reaction. Free Rad Biol Med. Oxford: Clarendon Press 1989; 188-276.

31. Maczurek A, Hager J, Kenklies M, et al. Vitamin C as an anti-inflammatory and neuroprotective treatment for Alzheimer's disease. Adv Drug Deliver Rev 2008; 60:1463-70.

32. Michiels $\mathrm{C}$, Raes M, Toussaint $\mathrm{O}$, et al. Importance of Se-glutathione peroxidase, catalase, and $\mathrm{Cu} / \mathrm{Zn}$-SOD for cell survival against oxidative stress. Free Radic Biol Med 1994; 17:235-48.

33. Tejada S, Roca C, Sureda A, et al. Antioxidant response analysis in the brain after pilocarpine treatments. Brain Res Bull 2006; 69:587-92.

34. Michiels C, Raes M, Toussaint O, Remacle J. Importance of Se-glutathione peroxidase, catalase, and $\mathrm{Cu} / \mathrm{Zn}$-SOD for cell survival against oxidative stress. Free Radic Biol Med 1994; 17:235-48.

35. Kudin AP, Bimpong-Buta NY, Vielhaber S, et al. Characterization of superoxide-producing sites in isolated brain mitochondria. J Biol Chem 2004; 279:4127-35.

36. Tran TD, Jackson $\mathrm{HD}$, Horn $\mathrm{KH}$, et al. Vitamin $\mathrm{E}$ does not protect against neonatal ethanol-induced cerebellar damage or deficits in eye blink classical conditioning in rats. Alcohol Clin Exp Res 2005; 29:117-29.

37. Dymond AM, Crandall PH. Oxygen availability and blood flow in the temporal lobes during spontaneous epileptic seizures in men. Brain Res 1976; 102:191-6.

38. Padayatty SJ, Katz A, Wang Y, et al. Vitamin C as an antioxidant: evaluation of its role in disease prevention. J Am Coll Nutr 2003; 22:18-35.

39. Padayatty SJ, Levine M. New insights into the physiology and pharmacology of vitamin C. CMAJ 2001; 164:353-5.

40. Carr A, Frei B. Does vitamin $\mathrm{C}$ act as a pro-oxidant under physiological conditions? FASEB J 1990a; 13:1007-24.

41. May JM, Qu Z, Li X. Requirement for GSH in recycling of ascorbic acid in endothelial cells. Biochem Pharmacol 2001; 62:873-81.

42. May JM, Qu ZC. Transport and intracellular accumulation of vitamin C in endothelial cells: relevance to collagen synthesis. Arch Biochem Biophys 2005; 434:178-86.

43. Rao AV, Balachandran B. Role of oxidative stress and antioxidants in neurodegenerative diseases. Nutr Neurosci 2002; 5:291-309.

44. Tanaka J, Toku K, Zhang B, Ishihara K, Sakanaka M, Maeda N. Astrocytes prevent neuronal death induced by reactive oxygen and nitrogen species. Glia 1999; 28:85-96.

45. Rice ME. Ascorbate regulation and its neuroprotective role in the brain. Trends in Neurosciences 2000; 23:209-16. 
46. Turski WA, Cavalheiro EA, Schwarz M, et al. Limbic seizures produced by pilocarpine in rats: behavioural, eletroencephalographic and neuropathological study. Behav Brain Res 1983; 9:315-36.

47. Draper HH, Hadley M. Malondialdehyde determination as an index of lipid peroxidation. Methods Enzymol 1990; 186:421-31.

48. Oliveira AA, Almeida JP, Freitas RM, et al. Effects of levetiracetam in lipid peroxidation level, nitrite-nitrate formation and antioxidant enzymatic activity in mice brain after pilocarpine-induced seizures. Cell Mol Neurobiol 2007; 27:395-406.

49. Freitas RM. The evaluation of effects of lipoic acid on the lipid peroxidation, nitrite formation and antioxidant enzymes in the hippocampus of rats after pilocarpine-induced seizures. Neurosci Lett 2009; 455:140-4.

50. Kawashima H, Inage Y, Ogihara M, et al. Serum and cerebrospinal fluid nitrite/nitrate levels in patients with rotavirus gastroenteritis induced convulsion. Life Sci 2004, 74:1397-405.

51. Green LC, Tannenbaum SR, Goldman P. Nitrate synthesis in the germfree and conventional rat. Science $1981 ; 212: 56-8$

52. Hayashi M. Oxidative stress in developmental brain disorders. Neuropathology 2009; 29:1-8.

53. Golden TR, Patel M. Catalytic Antioxidants and Neurodegeneration. Antioxid Redox Signal 2008

54. Lowry H, Rosebrough NJ, Farr AL, et al. Protein measurements with the folin phenol reagent. J Biol Chem 1991; 193:265-75.

55. Flohe L, Otting F. Superoxide dismutase assays. Methods Enzymol 1984; 105:93-104.

56. Chance B, Maehly AC. Assay catalases and peroxidases. Methods Enzymol 1955; 2:764-8

57. Chance B, Maehly AC. Assay catalases and peroxidases. Methods Enzymol 1955; 2:764-8. 


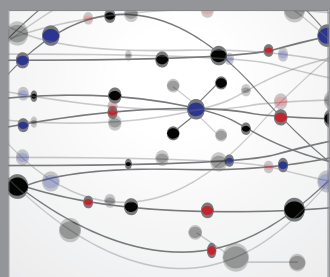

The Scientific World Journal
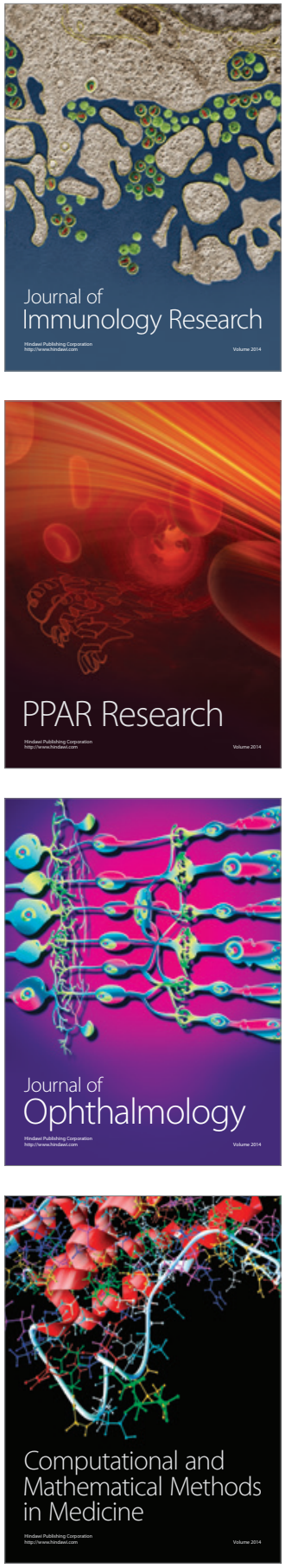

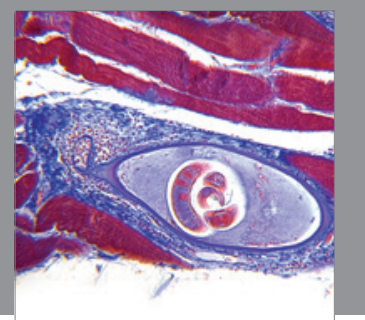

Gastroenterology

Research and Practice
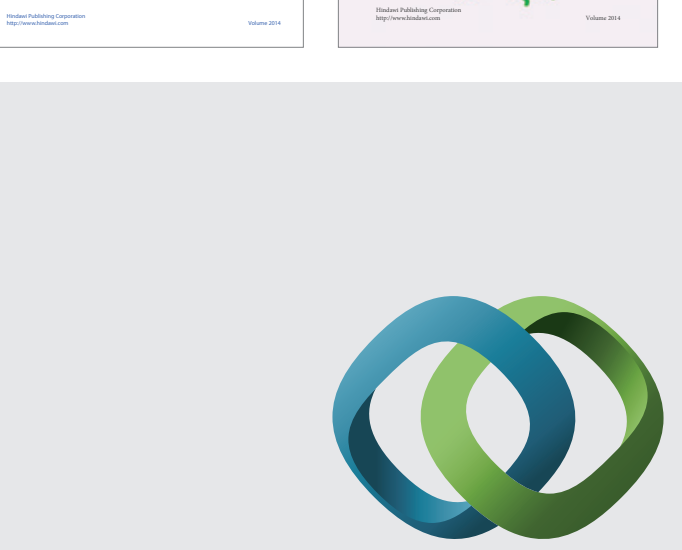

\section{Hindawi}

Submit your manuscripts at

http://www.hindawi.com
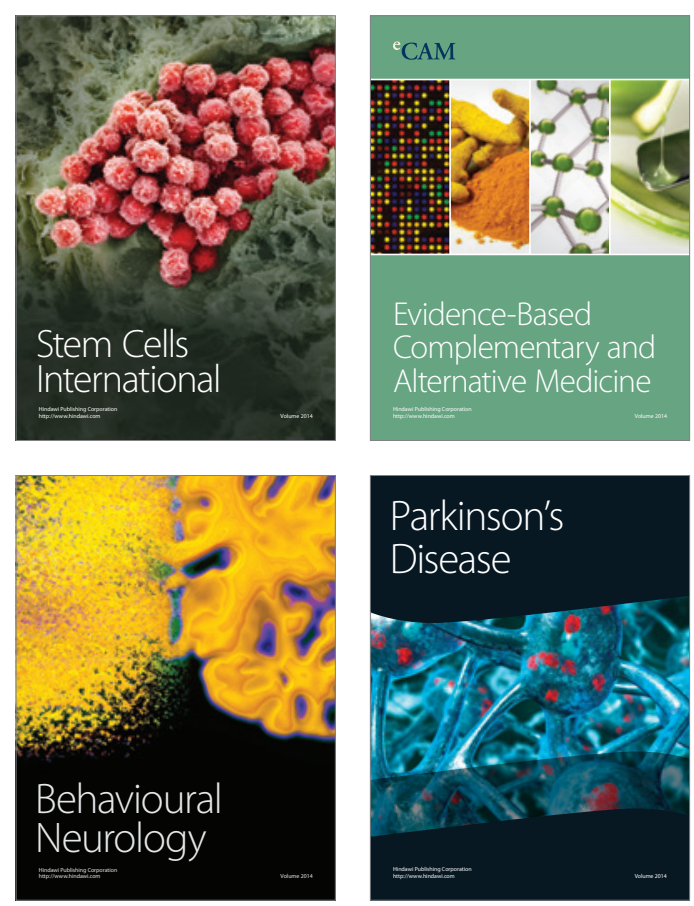

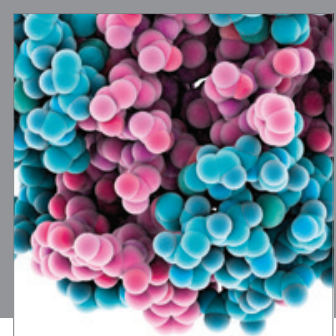

Journal of
Diabetes Research

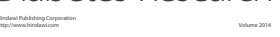

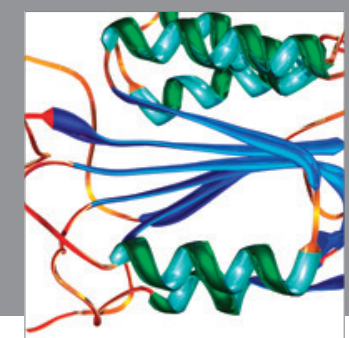

Disease Markers
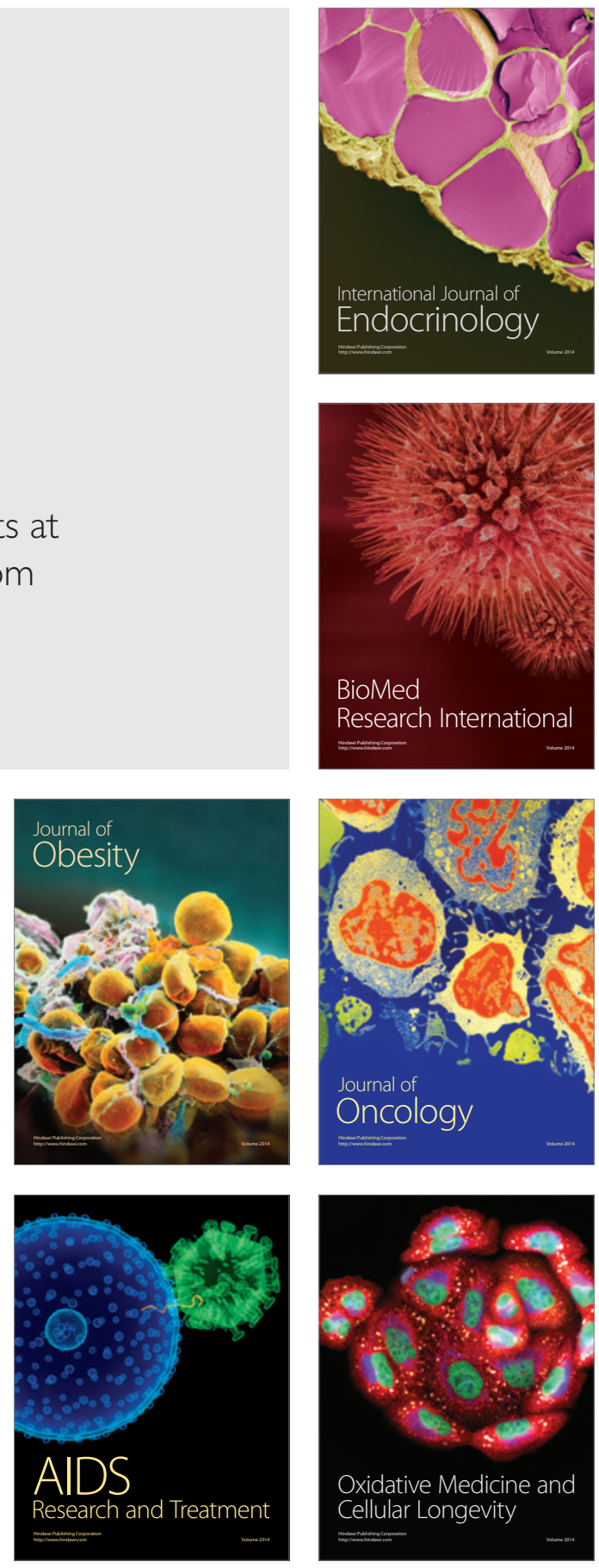